\title{
Kaempferol inhibits IL-1 $\beta$-induced proliferation of rheumatoid arthritis synovial fibroblasts and the production of COX-2, PGE2 and MMPs
}

\author{
HA-YONG YOON ${ }^{1 *}$, EUN-GYEONG LEE ${ }^{*}$, HYUN LEE $^{1}$, IN JIN CHO ${ }^{1}$, YUN JUNG CHOI $^{1}$, \\ MYUNG-SOON SUNG ${ }^{1}$, HAN-GYUL YOO ${ }^{2}$ and WAN-HEE YOO ${ }^{1}$
}

\begin{abstract}
${ }^{1}$ Department of Internal Medicine, Chonbuk National University Medical School and Research Institute of Clinical Medicine of Chonbuk National University Hospital, Chonbuk National University, Jeonju, Jeonbuk 561-180, Republic of Korea;

${ }^{2}$ Department of Pharmacy Practice, College of Pharmacy, University of Rhode Island, Kingston, RI 02881, USA
\end{abstract}

Received May 27, 2013; Accepted August 1, 2013

DOI: $10.3892 / \mathrm{ijmm} .2013 .1468$

\begin{abstract}
Inflammatory cytokines, matrix metalloproteinases (MMPs) and cyclooxygenase (COX)-2 released from rheumatoid arthritis synovial fibroblasts (RASFs) are involved in the destruction of both articular bone and cartilage. Kaempferol has been reported to act as an antioxidant and anti-inflammatory agent by inhibiting nitric oxide synthase and COX enzymes. The aim of the present study was to determine the effects of kaempferol on the interleukin-1 $\beta$ (IL-1 $\beta$ )-induced proliferation of RASFs and the production of MMPs, COX and prostaglandin E2 (PGE2) by RASFs. The proliferation of the RASFs stimulated with IL-1 $\beta$ and treated with/without kaempferol was evaluated by CCK-8 assay. The expression of MMPs, TIMP metallopeptidase inhibitor-1 (TIMP-1), COXs, PGE2 and that of intracellular MAPK signaling molecules, including p-ERK, p-p38, p-JNK and nuclear factor- $\kappa \mathrm{B}(\mathrm{NF}-\kappa \mathrm{B})$ was examined by immunoblotting or semi-quantitative reverse transcription-polymerase chain reaction (RT-PCR) and ELISA under the conditions described above. Kaempferol inhibited the proliferation of both unstimulated and IL-1 $\beta$-stimulated RASFs, as well as the mRNA and protein expression of MMP-1, MMP-3, COX-2 and PGE2 induced by IL-1 $\beta$. Kaempferol also inhibited the phosphorylation of ERK-1/2, p38 and JNK, as well as the activation of NF- $\kappa \mathrm{B}$ induced by IL-1 $\beta$. These results indicate that kaempferol inhibits synovial fibroblast prolifera-
\end{abstract}

Correspondence to: Professor Wan-Hee Yoo, Department of Internal Medicine, Chonbuk National University Medical School and Research Institute of Clinical Medicine of Chonbuk National University Hospital, Chonbuk National University, San 2-20 Geumam-dong, Deokjin-gu, Jeonju, Jeonbuk 561-180, Republic of Korea

E-mail: ywhim@jbnu.ac.kr

*Contributed equally

Key words: cyclooxygenase, interleukin-1 $\beta$, prostaglandin E2, matrix metalloproteinases, rheumatoid arthritis, kaempferol tion, as well as the production of and MMPs, COX-2 and PGE2, which is involved in articular inflammation and destruction in rheumatoid arthritis (RA). Our data suggest that kaempferol may be a novel therapeutic agent for the treatment of RA.

\section{Introduction}

Rheumatoid arthritis (RA) is a chronic inflammatory systemic disease of unknown etiology characterized by chronic synovitis with subsequent articular bone and cartilage destruction $(1,2)$. Chronic inflammation with hyperplasia of synovial lining cells, including synovial fibroblasts, are the histological characteristics of RA. When activated, rheumatoid arthritis synovial fibroblasts (RASFs) play a key role in the pathogenesis of RA synovitis through proliferation and resultant pannus formation. Inflammatory cytokines, matrix metalloproteinases (MMPs) and cyclooxygenase (COX)-2 released from RASFs are involved in the destruction of articular bone and cartilage $(1,2)$. On the basis that interleukin (IL)-1 $\beta$ induces the proliferation of RASFs, resulting in the production of high levels of MMPs and prostaglandin E2 (PGE2), it has become a major target of biological therapy.

Flavonoids are natural polyphenols present in a wide variety of fruits and vegetables (3) and have a number of biological properties, such as antiviral (4), antitumor (5), antioxidant (6) and anti-inflammatory properties (7). Kaempferol (3,5,7,4'-tetrahydroxy flavone), which is found in tea, propolis and grapefruit, is one of the most common dietary flavonoids (8). It has been used as a traditional therapeutic for a number of inflammatory disorders. Previous studies have demonstrated that kaempferol reduces lipopolysaccharide-induced COX-2 levels in RAW 264.7 cells (9) and inhibits reactive oxygen species production through the inhibition of inducible nitric oxide synthase (iNOS) and tumor necrosis factor (TNF)- $\alpha$ protein expression in aged gingival tissues (10). Kaempferol has also exhibited anti-inflammatory effects through the inhibition of IL-4 (11), COX-2 and C-reactive protein (CRP) expression and the downregulation of nuclear factor $-\kappa \mathrm{B}(\mathrm{NF}-\kappa \mathrm{B})$ in liver cells (12). Despite these anti-inflammatory effects of kaempferol and the critical role of RASFs in RA pathogenesis, to our 
knowledge, there are no studies to date on the effects of kaempferol on inflammatory reactions, including the production of MMPs, COX-2 and PGE2 by RASFs.

In the present study, we investigated the effects of kaempferol on the production of pro-inflammatory mediators, including MMPs, COX-2 and PGE2 produced by RASFs and the proliferation of these cells, following stimulation with IL-1 $\beta$. Intracellular signaling factors were evaluated to elucidate the mechanisms behind the effects of kaempferol. We demonstrate that kaempferol inhibits the IL-1 $\beta$-induced proliferation of RASFs and inflammatory reactions by inhibiting the activation of mitogen-activated protein kinases (MAPKs) and $\mathrm{NF}-\kappa \mathrm{B}$ pathways in RASFs.

\section{Materials and methods}

Reagents and antibodies. Recombinant human IL-1 $\beta$ was purchased from R\&D Systems (Minneapolis, MN, USA) and kaempferol were obtained from Sigma-Aldrich, Inc. (St. Louis, MO, USA) and dissolved in DMSO with a concentration of $100 \mathrm{mM}$ stock solution. Monoclonal antibodies (mAbs) against COX-2, MMP-1, MMP-3 and TIMP were purchased from Santa Cruz Biotechnology, Inc. (Santa Cruz, CA, USA). mAbs against NF- $\mathrm{B}$ (p65), IkB $\alpha$, ERK, p-ERK, JNK, p-JNK, p38, p-p38 and $\beta$-actin were purchased from Cell Signaling Technology (Beverly, MD, USA). Fetal bovine serum (FBS) was obtained from Gibco BRL/Life Technologies (Grand Island, NY, USA).

Isolation and culture of RASFs. Synovial tissues were obtained at the time of total knee arthroplasty from patients who fulfilled the American College of Rheumatology Criteria for RA (13), as previously described (14). Synovial tissue was digested for $2 \mathrm{~h}$ with $0.25 \%(\mathrm{w} / \mathrm{v})$ collagenase and was then suspended in RPMI-1640 medium with $10 \%$ (v/v) FBS, $100 \mathrm{U} / \mathrm{ml}$ of penicillin and $100 \mu \mathrm{g} / \mathrm{ml}$ of streptomycin. The cells were incubated at $37^{\circ} \mathrm{C}$ in $5 \% \mathrm{CO}_{2}$ for several days, after which the non-adherent cells were removed. Synovial fibroblasts from passages 3-7 were used for each experiment and were morphologically homogeneous and had the appearance of RASFs with typical fibroblastoid configuration under an inverse microscope. The purity of the cells was determined by flow cytometry using phycoerythrin (PE)-conjugated anti-Thy-1 (CD90) or anti-CD14 and fluorescein isothiocyanate (FITC)-conjugated anti-CD3 mAb (BD Pharmingen, San Diego, CA, USA). Informed consent was obtained from all patients, and the study protocol was approved by the Chonbuk National University Hospital Ethics Committee.

Cell viability analysis. Cell viability was determined by using the Cell Counting Kit-8 (CCK-8; Dojindo Laboratories, Japan) according to the manufacturer's instructions. CCK- 8 allows convenient assays using Dojindo's tetrazolium salt, 2-(2methoxy-4-nitrophenyl)-3-(4-nitrophenyl)-5-(2,4-disulfophenyl)2H-tetrazolium, monosodium salt (WST-8), which produces a water-soluble formazan dye upon bioreduction in the presence of an electron carrier, 1-methoxy phenazinium methylsulfate (PMS) (15). CCK-8 solution is added directly to the cells; no pre-mixing of the components is required. CCK- 8 is a sensitive non-radioactive colorimetric assay for determining the number of viable cells in cell proliferation and cytotoxicity assays. WST-8 is bioreduced by cellular dehydrogenases to an orange formazan product that is soluble in tissue culture medium. The amount of formazan produced is directly proportional to the number of living cells. RASFs $\left[1 \times 10^{5}\right.$ cells/well in Dulbecco's modified Eagle's medium (DMEM) containing 10\% (v/v) FCS in a 96-well U-bottom plate] were cultured in $200 \mu \mathrm{l}$ medium/ well in the presence or absence of $1.0 \mathrm{ng} / \mathrm{ml} \mathrm{IL-1 \beta}$ and/or kaempferol $(100 \mu \mathrm{M})$ for 2 days according to the results of a dose-dependent examination and a previous report (15), while the control RASFs were incubated in DMEM with DMSO. CCK-8 $(20 \mu \mathrm{l})$ was added to each well of the plate and the cells were incubated for 2-3 h. The absorbance was measured at $450 \mathrm{~nm}$ using a microplate reader to determine the cell viability in each well.

Analysis of apoptosis. To evaluate the effects of kaempferol on the apotosis of RASFs, RASFs were incubated in DMEM for $24 \mathrm{~h}$ with kaempferol $(100 \mu \mathrm{M})$, while the control RASFs were incubated in DMEM with DMSO. The cells were then trypsinized and collected for the detection of apoptosis with an Annexin V-FITC Apoptosis Detection kit according to the manufacturer's instructions. Briefly, the cells were washed twice with cold PBS and resuspended in $500 \mathrm{ml}$ of binding buffer (10 mM HEPES-NaOH pH 7.4, 140 mM NaCl, $2.5 \mathrm{mM}$ $\mathrm{CaCl}_{2}$ ) at a concentration of $0.5 \times 10^{5}$ cells $/ \mathrm{ml}$. After the addition of $5 \mu \mathrm{l}$ of Annexin V-FITC solution and propidium iodide (PI; $5 \mu \mathrm{l}$ ), the cells were incubated for $15 \mathrm{~min}$ at room temperature. The cells were analyzed using a flow cytometer (Beckman Coulter, Fullerton, CA, USA).

RNA isolation and semi-quantitative reverse transcription-polymerase chain reaction (RT-PCR( of COX, MMPs and TIMP. Total RNA was extracted from the cultured RASFs using TRIzol reagent (Invitrogen, Carlsbad, CA, USA) following the manufacturer's instructions. RNA $(1 \mu \mathrm{g})$ was reverse-transcribed using the Maxime RT Premix kit (iNtRON Biotechnology, Seoul, Korea). cDNA was amplified using the following primer sets: MMP-1 sense, 5'-GAA GGA GAT GAA GCA GCC CAG ATG T-3' and antisense, 5'-CAG TTG TGG CCA GAA AAC AGA AGT GAA A-3'; MMP-3 sense, 5'-GAC ACC AGC ATG AAC CTT GTT-3' and antisense, 5'-GGA ACC GAG TCA GGA CTA TG-3'; TIMP-1 sense, 5'-CCT TCT GCA ATT CCG ACC TCG TC-3' and antisense, 5'-CGG GCA GGA TTC AGG CTA TCT GG-3'; COX-2 sense, 5'-TCC TTG CTG TTC CCA CCC ATG-3' and antisense, 5'-CAT CAT CAG ACC AGG CAC CAG-3'; GAPDH sense, 5'-AAA TCA AGT GGG GCG ATG CT-3' and antisense, 5'-AGC TTC CCG TTC AGC TCA GG-3'. PCR products were electrophoresed using $1 \%$ agarose gels and visualized by staining with ethidium bromide. Densitometric analysis was performed on the relative intensity of each band using the Multi Gauge software v3.0 (Fujifilm, Tokyo, Japan).

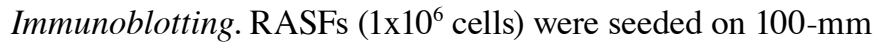
culture dishes and harvested in phosphate-buffered saline (PBS). After washing with PBS, cell pellets were lysed with the lysis buffer [20 mM HEPES, pH 7.2, 1\% Triton X-100, $150 \mathrm{mM} \mathrm{NaCl}, 0.1 \mathrm{mM}$ phenylmethylsulfonyl fluoride (PMSF), $1 \mathrm{mM}$ EDTA and $1 \mu \mathrm{g} / \mathrm{ml}$ aprotinin]. Following incubation for 
A

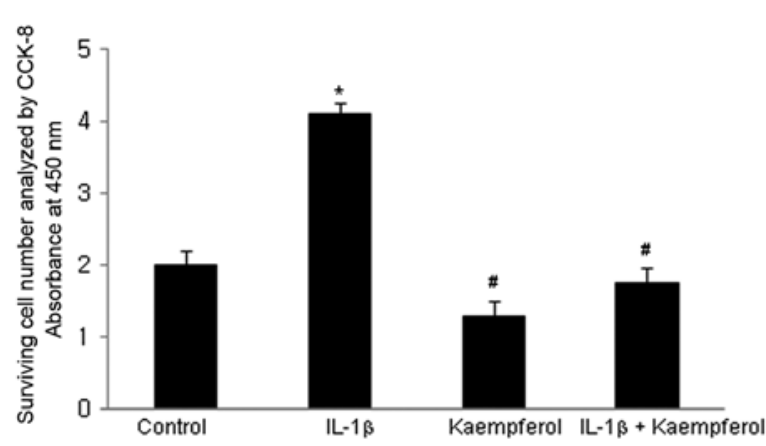

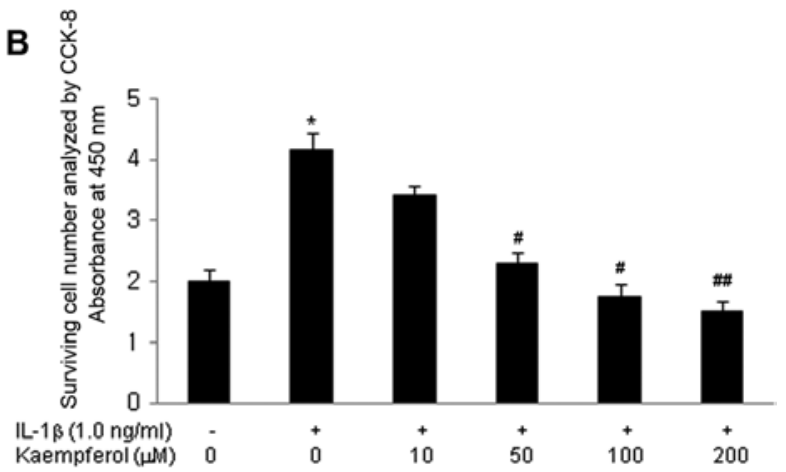

Figure 1. Interleukin-1 $\beta$ (IL-1 $\beta$ ) increases the proliferation of rheumatoid arthritis synovial fibroblasts (RASFs) in a dose-dependent manner and kaempferol inhibits the IL-1 $\beta$-induced proliferation of RASFs. (A) To determine the effects of kaempferol on the IL-1 $\beta$-induced proliferation of RASFs, kaempferol $(100 \mu \mathrm{M})$ was added to the RASF cultures with/without IL-1 $\beta(1.0 \mathrm{ng} / \mathrm{ml})$ for 3 days and CCK- 8 assay was performed. Kaempferol significantly inhibited the IL-1-induced proliferation of RASFs after $2-3$ days of culture $(\mathrm{P}<0.05)$. ${ }^{*} \mathrm{P}<0.05$ vs. no IL-1 $\beta$ and kaempferol (control), ${ }^{\#} \mathrm{P}<0.05$ vs. IL-1 $\beta$ without kaempferol. (B) To determine the dose-dependent effects of kaempferol on the IL-1 $\beta$-induced proliferation of RASFs, various doses of kaempferol (10, 50,100 and $200 \mu \mathrm{M})$ were added to the RASF cultures with IL-1 $\beta(1.0 \mathrm{ng} / \mathrm{ml})$ for 2 days and CCK- 8 assay was performed. Kaempferol inhibited the IL-1 $\beta$-induced proliferation of RASFs in a dose-dependent manner. ${ }^{*} \mathrm{P}<0.05$ vs. no IL-1 $\beta$ and kaempferol, ${ }^{\#} \mathrm{P}<0.05$ vs. IL-1 $\beta$ without kaempferol, ${ }^{\# \#} \mathrm{P}<0.01$ vs. IL-1 $\beta$ without kaempferol.

30 min at $4^{\circ} \mathrm{C}$, cellular debris was removed by centrifugation at $100,000 \mathrm{x} \mathrm{g}$ for $30 \mathrm{~min}$ and the supernatants were analyzed by sodium dodecyl sulfate-polyacrylamide gel electrophoresis (SDS-PAGE). To determine membrane COX-2 expression in RASFs, cell membranes were prepared from isolated RASFs as previously described (16). To determine NF- $\kappa \mathrm{B}$ (p65) expression, nuclear extracts were prepared using a previously described method (14). To determine cytoplasmic IkB $\alpha$ expression, cytoplasmic extracts were prepared as previously described (14).

Protein concentration was determined using the Bio-Rad protein assay reagent (Bio-Rad Laboratories, Hercules, CA, USA). Samples $(50 \mu \mathrm{g})$ were prepared with $4 \mathrm{vol}$ of $0.5 \mathrm{M}$ Tris buffer ( $\mathrm{pH}$ 6.8) containing 4\% SDS, $20 \%$ glycerol and $0.05 \%$ bromophenol blue at $95^{\circ} \mathrm{C}$ for $5 \mathrm{~min}$. SDS-PAGE was performed on a $10 \%$ slab gel. Proteins were transferred onto a nitrocellulose membrane. The membrane was washed in blocking buffer (10 mM Tris- $\mathrm{HCl} \mathrm{pH} 8.0,150 \mathrm{mM} \mathrm{NaCl}, 5 \%$ fat-free milk) for $60 \mathrm{~min}$ at room temperature with shaking and then washed with TBST (TBS, $0.01 \%$ Tween-20). Primary antibodyies (10 $\mu \mathrm{g} / \mathrm{ml})$ against MMP-1, MMP-3, TIMP, COX-2, ERK, p-ERK-1/2, p-38, p-p38 MAPK, JNK, p-JNK, NF(p65), IkB $\alpha$ and $\beta$-actin were then added followed by incubation at $4^{\circ} \mathrm{C}$ for $4 \mathrm{~h}$. The secondary HRP-conjugated antibody was goat anti-mouse IgG (Santa Cruz Biotechnology, Inc.). Reactive proteins were detected by enhanced chemiluminescence (ECL; Amersham Life Sciences, Arlington Heights, IL, USA) using Fujifilm LAS-3000 (Fujifilm).

Assay of PGE2 production. RASFs (1 $\times 10^{4}$ cells) were grown in $25 \mathrm{~cm}^{2}$ tissue-culture flasks for $48 \mathrm{~h}$ before treatment. After washing with PBS ( $\mathrm{pH} 7.4$ ), cells were pre-treated with IL-1 $\beta$ $(1.0 \mathrm{ng} / \mathrm{ml})$ or kaempferol $(100 \mu \mathrm{M})$ at $37^{\circ} \mathrm{C}$ for $48 \mathrm{~h}$ in DMEM containing $10 \%(\mathrm{v} / \mathrm{v}) \mathrm{FCS}$ in an atmosphere of $5 \% \mathrm{CO}_{2}$, while the control RASFs were incubated in DMEM with DMSO. The culture supernatant described above was collected at 2 days. The level of PGE2 in the medium was determined by ELISA (R\&D Systems) in accordance with the instructions of the manufacturer.
Statistical analysis. All data are expressed as the means \pm SD of the results of 3 experiments with different RASFs and all data were analyzed using SPSS 12.0 software. Group mean values were compared using the Student's t-test or ANOVA where appropriate. P-values $<0.05$ were considered to indicate statistically significant differences.

\section{Results}

Kaempferol inhibits the IL-1 $\beta$-induced proliferation of RASFs. The effect of kaempferol on the growth ability of RASFs was initially evaluated. Cell proliferation was measured following treatment with IL- $1 \beta$ for 3 days; IL- $1 \beta$ is a well known potent growth-promoting factor for RASFs (17). Cell proliferation was assayed as described in Materials and methods. IL-1 $\beta$ increased the proliferation of RASFs in a dose-dependent manner (from 0.1 to $10 \mathrm{ng} / \mathrm{ml}$ ). To examine the effects of kaempferol on the IL-1 $\beta$-induced proliferation of RASFs, kaempferol $(100 \mu \mathrm{M})$ was added to the RASF cultures with/ without IL-1 $\beta(1.0 \mathrm{ng} / \mathrm{ml})$ for 2 days and the CCK-8 assay was performed. IL-1 $\beta$ significantly increased the proliferation of RASFs compared with the control cells cultured in DMSO without IL-1 $\beta$ and kaempferol $(\mathrm{P}<0.05)$ (Fig. 1A). Kaempferol significantly inhibited the proliferation of RASFs treated with or without IL-1 $\beta(\mathrm{P}<0.05)$. Various doses of kaempferol $(10$, $50,100,200 \mu \mathrm{M})$ were added to the RASF cultures with IL-1 $\beta$ (1.0 ng/ml) for 2 days and CCK-8 assay was performed. The inhibitory effects of kaempferol were significantly enhanced in a dose-dependant manner (Fig. 1B).

Kaempferol induces the apoptosis of RASFs. To elucidate the underlying mechanisms by which kaempferol inhibits the IL-1 $\beta$-induced proliferation of RASFs, the effects of kaempferol on the apoptosis of RASFs were examined by flow cytometry and staining with Annexin V and PI. The percentage of Annexin V-positive cells was significantly increased in the RASFs treated with kaempferol compared with the cells cultured in DMEM with DMSO without kaempferol $(\mathrm{P}<0.05)$ (Fig. 2). 

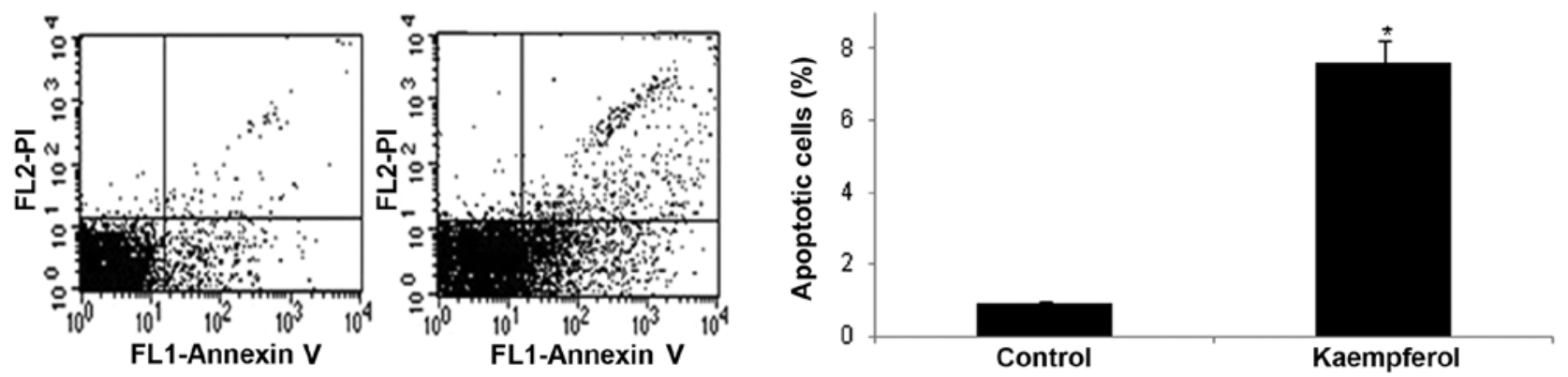

Figure 2. Kaempferol induces the apoptosis of rheumatoid arthritis synovial fibroblasts (RASFs). To determine the exact cause of the decreased proliferation induced by kaempferol, the effects of kaempferol on the apoptosis of RASFs were investigated by flow cytometry. RASFs (1x10 $)$ were cultured in 33-mm dishes in DMEM with DMSO in the presence or absence of kaempferol $(100 \mu \mathrm{M})$. Following culture for $24 \mathrm{~h}$, the cells were stained with Annexin V and propidium iodide (PI) and analyzed by flow cytometry. Kaempferol increased the apoptosis of RASFs compared with the control cells cultured in DMSO without kaempferol. ${ }^{*} \mathrm{P}<0.05$ vs. no kaempferol.

A

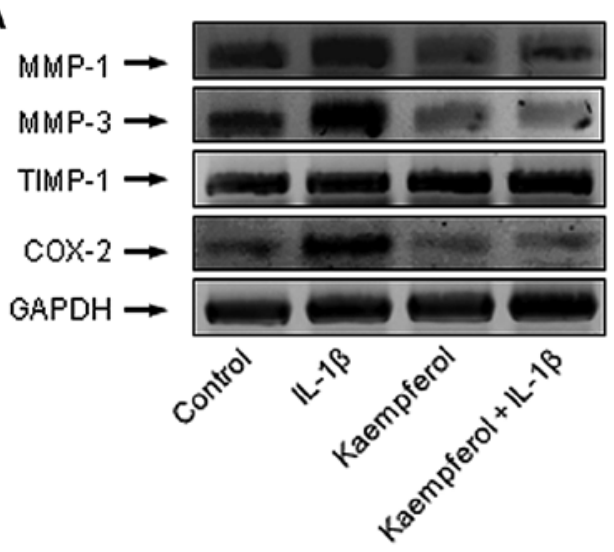

B

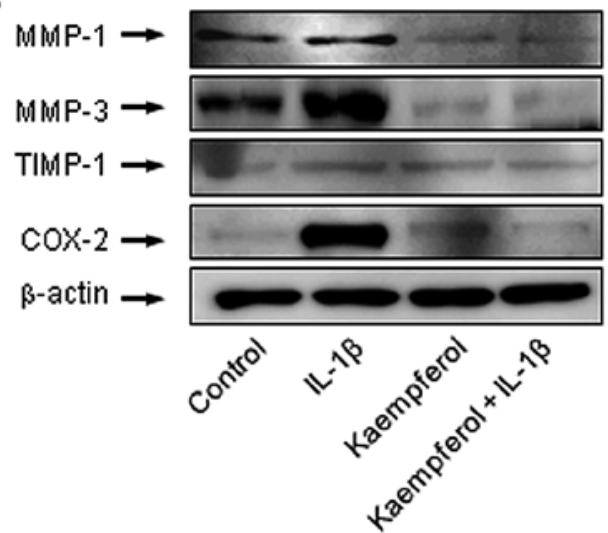

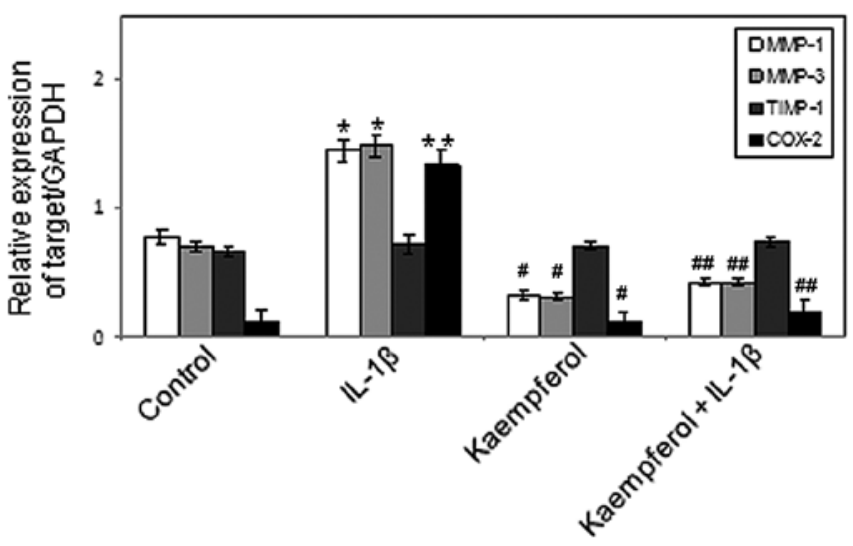

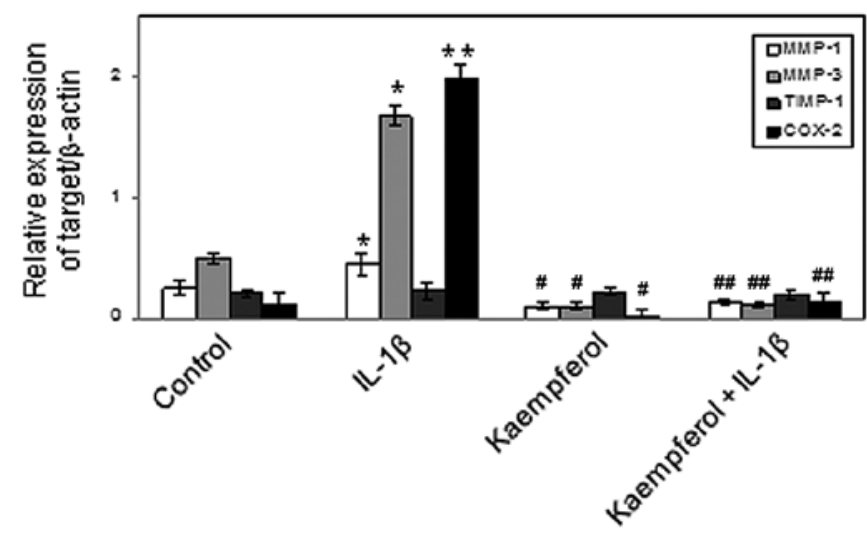

Figure 3. Kaempferol inhibits interleukin-1 $\beta$ (IL-1 $\beta$ )-induced production of matrix metalloproteinases (MMPs) and cyclooxygenase (COX)-2 in rheumatoid arthritis synovial fibroblasts (RASFs). To determine the mRNA and protein expression of MMP-1, MMP-3, TIMP-1 and COX-1 and COX-2, RASFs $\left(1 \times 10^{6}\right.$ cells) were cultured for 2 days with/without IL- $1 \beta(1.0 \mathrm{ng} / \mathrm{ml})$ and kaempferol $(100 \mu \mathrm{M})$. RNA and protein were extracted from the RASFs and analyzed by (A) RT-PCR and (B) western blot analysis. IL-1 $\beta$ enhanced the protein expression of MMP-1, MMP-3, TIMP-1 and COX-2 compared with the cells cultured without IL-1 $\beta$. Kaempferol inhibited the IL-1 $\beta$-induced protein expression of MMP-1, MMP-3 and COX-2. Results are presented as the means \pm SD. $n=3$. ${ }^{*} \mathrm{P}<0.05$ or ${ }^{* *} \mathrm{P}<0.01$ vs. no IL-1 $\beta$ and kaempferol, ${ }^{\#} \mathrm{P}<0.05$ vs. no IL-1 $\beta$ and kaempferol, ${ }^{\# \#} \mathrm{P}<0.05$ vs. IL- $1 \beta$ without kaempferol.

Effects of kaempferol on IL-1 $\beta$-induced MMP, TIMP-1 and COX mRNA expression in RASFs. RT-PCR was performed to determine the mRNA expression of MMP-1, MMP-3 and TIMP-1 in the monocultured RASFs. RASFs were stimulated with IL-1 $\beta(1.0 \mathrm{ng} / \mathrm{ml})$ for $48 \mathrm{~h}$ in the presence or absence of kaempferol $(100 \mu \mathrm{M})$. IL-1 $\beta$ enhanced the mRNA expression of MMP-1 and MMP-3 in RASFs $(\mathrm{P}<0.05)$, but not that of TIMP-1. Kaempferol inhibited the effects of IL-1 $\beta$ on the
mRNA expression of MMP-1 and MMP-3 ( $\mathrm{P}<0.05)$ (Fig. 3A). IL- $1 \beta$ also enhanced the mRNA expression of COX-2 in RASFs $(\mathrm{P}<0.01)$, but not that of COX-1 (data not shown). Kaempferol inhibited the IL-1 $\beta$-induced COX-2 mRNA expression $(\mathrm{P}<0.05)$ (Fig. 3A). Kaempferol also significantly decreased the mRNA expression of MMP-1, MMP-3 and COX-2 compared with the control cells cultured in DMSO without IL-1 $\beta$ and kaempferol $(\mathrm{P}<0.05)$. 


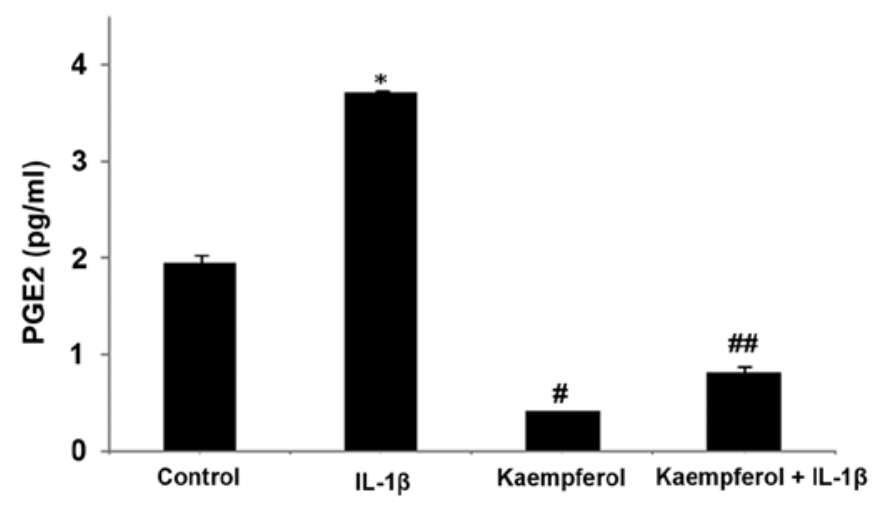

Figure 4. Prostaglandin E2 (PGE2) production was inhibited by treatment with kaempferol. Rheumatoid arthritis synovial fibroblasts (RASFs; $1 \times 10^{4}$ cells) were grown in $25 \mathrm{~cm}^{2}$ tissue-culture flasks for $48 \mathrm{~h}$ and were starved serum overnight prior to stimulation. RASFs were cultured for 2 days with/without interleukin (IL)-1 $\beta(1.0 \mathrm{ng} / \mathrm{ml})$ and kaempferol $(100 \mu \mathrm{M})$. The production of PGE2 by RASFs was evaluated by ELISA. IL-1 $\beta$-induced PGE2 production was significantly inhibited by kaempferol. Results are presented as the means $\pm \mathrm{SD}, \mathrm{n}=3,{ }^{*}, \mathrm{P}<0.05$ vs. no IL- $1 \beta$ and kaempferol, ${ }^{\# \#} \mathrm{P}<0.05$ vs. IL- $1 \beta$ without kaempferol.

Effects of kaempferol on IL-1 $\beta$-induced MMP, TIMP-1 and $C O X$ protein expression in RASFs. To determine the protein expression of MMPs, TIMP-1 and COX in the monocultured RASFs, we performed western blot analysis. RASFs were stimulated with IL-1 $\beta(1.0 \mathrm{ng} / \mathrm{ml})$ for $48 \mathrm{~h}$ in the presence or absence of kaempferol $(100 \mu \mathrm{M})$. IL- $1 \beta$ enhanced the protein expression of MMP-1 and MMP-3 in RASFs $(\mathrm{P}<0.05)$, but not that of TIMP-1; its effects on protein expression were similar to those on mRNA expression. Kaempferol inhibited the IL-1 $\beta$-induced protein expression of MMP-1 and MMP-3 $(\mathrm{P}<0.05)$ (Fig. 3B). IL-1 $\beta$ also enhanced the protein expression of COX-2 in RASFs ( $p<0.01)$, but not that of COX-1 (data not shown). Kaempferol inhibited the IL-1 $\beta$-induced protein expression of COX-2 ( $\mathrm{P}<0.05)$ (Fig. 3B). Kaempferol also significantly decreased the protein expression of MMP-1, MMP-3 and COX-2 compared with the control cells cultured in DMSO without IL-1 $\beta$ and kaempferol $(\mathrm{P}<0.05)$.

Kaempferol inhibits $I L-1 \beta$-induced PGE2 production in $R A S F s$. To confirm the effects of kaempferol on the IL-1 $\beta$ induced production of PGE2 by RASFs, we examined the concentration of PGE2 in the culture supernatant. RASFs $\left(1 \times 10^{4}\right.$ cells) were grown in $25 \mathrm{~cm}^{2}$ tissue-culture flasks for $48 \mathrm{~h}$ before and after treatment with IL-1 $\beta(1.0 \mathrm{ng} / \mathrm{ml})$ and/or kaempferol $(100 \mu \mathrm{M})$. PGE2 production was increased following treatment with IL-1 $\beta(\mathrm{P}<0.05)$ compared with the control cells cultured with DMSO without IL-1 $\beta$, and it was significantly inhibited by treatment with kaempferol at $48 \mathrm{~h}$ $(\mathrm{P}<0.05)$ (Fig. 4); the effects of kaempferol on PGE2 were similar to those on COX-2 expression. Kaempferol also significantly decreased the production of PGE2 compared with the control cells cultured in DMSO without IL-1 $\beta$ and kaempferol $(\mathrm{P}<0.05)$ (Fig. 4).

Effects of kaempferol on IL-1 $\beta$-induced signaling pathways in RASFs. To demonstrate the involvement of the signal transduction pathways and to elucidate the mechanisms behind the effects of kaempferol on IL-1 $\beta$-induced RASF proliferation and the production of MMPs, COX-2 and PGE2, the activation of MAPKs and NF- $\mathrm{BB}$ was evaluated in the RASFs. IL-1 $\beta$ phosphorylated intracellular MAPKs, including ERK, p-38 and JNK and kaempferol significantly inhibited the IL-1 $\beta$-induced intracellular MAPK activation (Fig. 5A). The activation of $\mathrm{NF}-\kappa \mathrm{B}, \mathrm{p} 65$ and the degradation of cytoplasmic $\mathrm{IkB} \alpha$ was observed in the RASFs treated with IL-1 $\beta$. The effects of IL-1 $\beta$ on $\mathrm{NF}-\kappa \mathrm{B}$ activation were abrogated by kaempferol (Fig. $5 \mathrm{~B}$ ). Kaempferol also inhibited the activation of the above intracellular signaling pathways compared with the control cells cultured in DMSO without IL-1 $\beta$ and kaempferol. These results indicate that kaempferol inhibits the IL- $1 \beta$-induced proliferation of RASFs, the expression of COX-2 and the production of PGE2 by inhibiting the activation of intracellular MAPK and $\mathrm{NF}-\kappa \mathrm{B}$ pathways.

\section{Discussion}

In this study, we demonstrate that kaempferol induces the apoptosis of RASFs and inhibits the IL- $1 \beta$-induced proliferation of RASFs. It inhibits the activation of the MAPK, ERK1/2, p-38 and $\mathrm{JNK}$ and $\mathrm{NF}-\kappa \mathrm{B}$ signaling pathways, resulting in the decreased expression of MMPs and COX-2, as well as in the decreased production of PGE2 by RASFs. These findings suggest that kaempferol may be used as a novel therapeutic agent for the management of RA by decreasing synovial inflammation.

Kaempferol, a polyphenolic flavonoid extracted from fenugreek seeds, has been shown to have strong antioxidant and anti-inflammatory properties (18). Previous studies have demonstrated that kaempferol reduces lipopolysaccharide-induced COX-2 levels in RAW 264.7 cells (9) and inhibits reactive oxygen species production through the inhibition of iNOS and TNF- $\alpha$ protein expression in aged gingival tissues (10). Kaempferol has also exhibited anti-inflammatory effects through the inhibition of IL-4 (11), COX-2 and CRP expression and the downregulation of NF- $\kappa \mathrm{B}$ in liver cells (12). Compared with other daily dietary flavonols, kaempferol has been reported to be associated with a decreased risk of various types of cancer (19-21). However, to our knowledge, there are no reports to date on the effects of kaempferol on inflammatory reactions, including the production of MMPs, COX-2 and PGE2 by RASFs and the mechanisms involved, which play a crucial role in the pathogenesis of synovitis and articular destruction in RA.

In RA, one of the most striking features is the hyperplasia of synovial fibroblasts in the lining layer which is considered to be the main mechanism responsible for the hyperplasic growth of the RA synovium and eventually destroys articular bone and cartilage $(22,23)$. Given that the IL-1 $\beta$-induced proliferation of RASFs is closely involved in inflammatory synovitis joint destruction, the response of RASFs to IL-1 $\beta$ plays a crucial role in the physiopathology of RA (24). Our study demonstrated that kaempferol significantly induced the apoptosis of RASFs and inhibited the proliferation of unstimulated and IL- $1 \beta$-stimulated of RASFs in a dose- and time-dependent manner.

Pro-inflammatory cytokines, including IL-1 $\beta$ enhance the expression of COX-2 and MMPs in human RASFs $(25,26)$. MMPs are involved in the destruction of the extracellular 
A
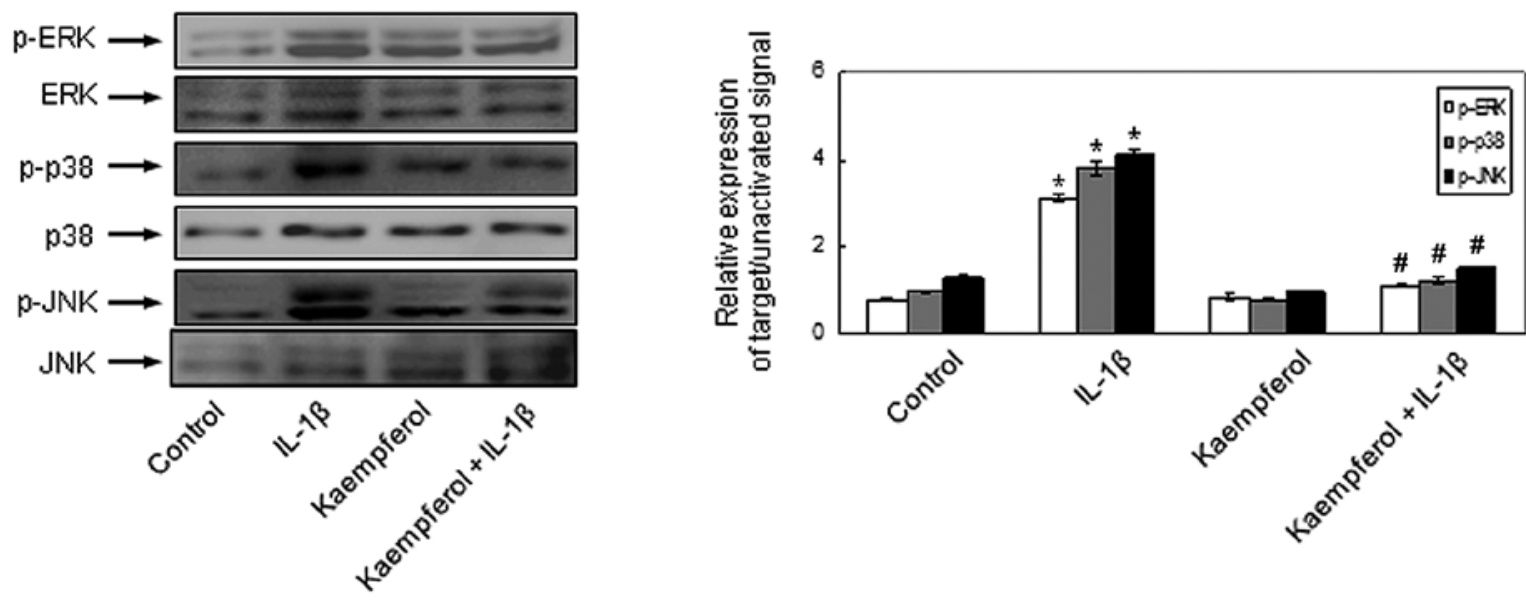

B
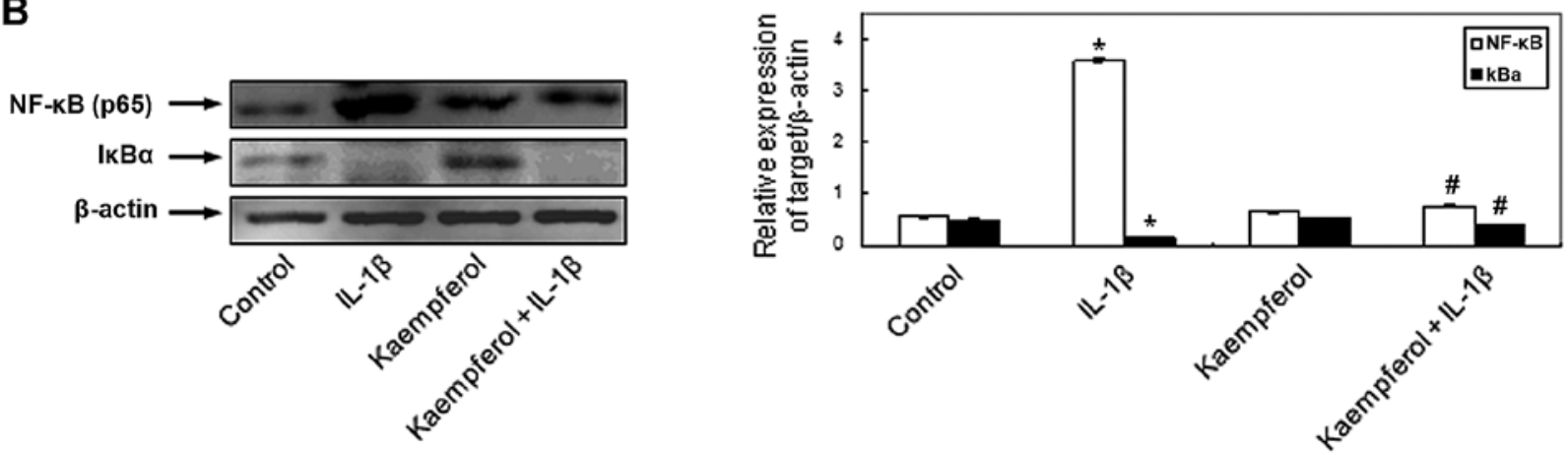

Figure 5. Effects of kaempferol on the interleukin-1 $\beta$ (IL-1ß)-induced activation of mitogen-activated protein kinase (MAPK) signaling pathways and nuclear factor- $\mathrm{KB}$ (NF- $\mathrm{\kappa B}$ ) activation in rheumatoid arthritis synovial fibroblasts (RASFs). To evaluate the mechanisms behind the effects of kaempferol on IL-1 $\beta$ in

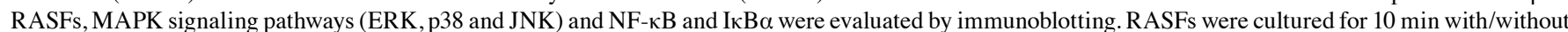
IL-1 $\beta(1.0 \mathrm{ng} / \mathrm{ml})$ and kaempferol $(100 \mu \mathrm{M})$. IL-1 $\beta$ enhanced the phosphorylation of ERK, p38 and JNK and kaempferol inhibited the IL-1 $\beta$-induced activation of p38 and JNK (A). IL-1 $\beta$ activated nuclear NF- $\mathrm{kB}$ and decreased cytoplasmic IkB $\alpha$ and kaempferol inhibited the IL-1 $\beta$-induced activation of NF- $\mathrm{B} B$ (B). Results are presented as the means $\pm \mathrm{SD}, \mathrm{n}=3 ;{ }^{*} \mathrm{P}<0.01$ vs. no IL-1 $\beta$-and kaempferol, ${ }^{*} \mathrm{P}<0.05$ vs. IL-1 $\beta$ without kaempferol.

matrix in articular structures and COX-2 converts free arachidonic acid into prostaglandins, including a variety of bio-active compounds [prostacyclin (PGI2), thromboxane A2 (TXA2), PGE2 and prostaglandin D2 (PGD2)]. PGE2, a pleiotropic mediator of inflammation, is involved in several pathological processes and plays a critical role in eliciting the signs and symptoms of inflammation in the joints of RA patients when produced in excess (27). We also found that kaempferol inhibits the expression of MMPs and COX-2 and PGE2 synthesis in a dose-dependent manner in both unstimulated and IL-1 $\beta$-stimulated RASFs. This suggests that kaempferol may be a potent therapeutic compound for RA. However, further studies are required to investigate the overall effects of kaempferol on the pathophysiology of synovitis in in vivo systems, such as animal models of RA and collagen-induced arthritis (CIA) and to elucidate the underlying mechanisms.

$N F-\kappa B$ and MAPKs participate in the pathogenic mechanisms of inflammation and the destruction of joints in RA. It is known that NF- $\mathrm{KB}, \mathrm{JNK}, \mathrm{p}-38$ and ERK are expressed in cultured RASFs and are readily activated by IL- $1 \beta$ and TNF- $\alpha(13,28,29)$. Numerous studies have demonstrated that inhibitors of MAPKs or NF- $\mathrm{B}$ decrease synovial inflammation, bone destruction and cartilage damage in animal models of arthritis, including adjuvant arthritis in rats and CIA in mice $(30,31)$. It has been described that kaempferol suppresses
IL-1 $\beta$-induced inflammatory responses by regulating signaling pathways, including NF- $\kappa$ B activation and MAPK phosphorylation in human airway epithelial cells (32). In human synovial cells, the addition of kaempferol has been shown to suppress the TNF- $\alpha$-induced increase in the mRNA expression of IL-8 and monocyte chemotactic protein-1 (MCP-1) in a dose-dependent manner by inhibiting the activation of $\mathrm{NF}-\kappa \mathrm{B}$ induced by TNF- $\alpha$ (33). In this study, to elucidate the mechanisms behind the effects of kaempferol on IL-1 $\beta$-induced RASF proliferation, the expression of COX-2 and the production of PGE2, as well as the activation of MAPKs and NF- $\kappa \mathrm{B}$ were examined. Our results revealed that kaempferol inhibited the IL-1 $\beta$-induced activation of NF- $\kappa \mathrm{B}$ and the phosphorylation of ERK, p-38 and JNK. However, further investigations are required to elucidate the mechanisms by which kaempferol suppresses NF- $\kappa \mathrm{B}$ activation, which components of NF- $\kappa \mathrm{B}$ are suppressed, and which intracellular signaling factors are more specifically or directly involved in the effects of kaempferol on the proliferation of RASFs and PGE2 production.

To our knowledge, this is the first study to report that kaempferol induces the apoptosis of RASFs and inhibits the IL-1 $\beta$-induced proliferation of RASFs. It also suppresses the expression of MMP-1, MMP-3 and COX-2 and the production of PGE2 by RASFs by inhibiting the IL- $\beta$-induced activation of $N F-\kappa B$ and the phosphorylation of the MAPK pathways, 
p-38, JNK and ERK. Based on our findings, kaempferol has great potential as a novel therapeutic agent and may prove useful in the treatment of inflammatory diseases, including RA. However, further studies are required to elucidate the exact mechanisms underlying the inhibitory effects of kaempferol on synovial cell proliferation and inflammatory reactions.

\section{Acknowledgements}

The present study was supported by a grant from the Korea Healthcare technology R\&D Project, Ministry for Health, Welfare and Family Affairs, Korea (A084144).

\section{References}

1. Henderson B, Hardinham T, Blake S and Lewthwaite $\mathrm{J}$ Experimental arthritis models in the study of the mechanisms of articular cartilage loss in rheumatoid arthritis. Agents Actions Suppl 39: 15-26, 1993.

2. Han MK, Kim JS, Park BH, et al: NF-kappaB-dependent lymphocyte hyperadhesiveness to synovial fibroblasts by hypoxia and reoxygenation: potential role in rheumatoid arthritis. J Leukoc Biol 73: 525-529, 2003.

3. Bosetti C, Rossi M, McLaughlin JK, et al: Flavonoids and the risk of renal cell carcinoma. Cancer Epidemiol Biomarkers Prev 16: 98-101, 2007.

4. Guo Q, Zhao L, You Q, et al: Anti-hepatitis B virus activity of wogonin in vitro and in vivo. Antiviral Res 74: 16-24, 2007.

5. Cárdenas M, Marder M, Blank VC and Roquin LP: Antitumor activity of some natural flavonoids and synthetic derivatives on various human and murine cancer cell lines. Bioorg Med Chem 14: 2966-2971, 2006.

6. Burda S and Oleszek W: Antioxidant and antiradical activities of flavonoids. J Agric Food Chem 49: 2774-2779, 2001.

7. González-Gallego J, Sánchez-Campos S and Tuñón MJ: Anti-inflammatory properties of dietary flavonoids. Nutr Hosp 22: 287-293, 2007.

8. Olszewska M: Separation of quercetin, sexangularetin, kaempferol and isorhamnetin for simultaneous HPLC determination of flavonoid aglycones in inflorescences, leaves and fruits of three Sorbus species. J Pharm Biomed Anal 48: 629-635, 2008.

9. Kim SK, Kim HJ, Choi SE, Park KH, Choi HK and Lee MW: Anti-oxidative and inhibitory activities on nitric oxide (NO) and prostaglandin $\mathrm{E}_{2}(\mathrm{COX}-2)$ production of flavonoids from seeds of Prunus tomentosa Thunberg. Arch Pharm Res 31: 424-428, 2008

10. Kim HK, Park HR, Lee JS, Chung TS, Chung HY and Chung J: Down-regulation of iNOS and TNF-alpha expression by kaempferol via NF-kappaB inactivation in aged rat gingival tissues. Biogerontology 8: 399-408, 2007.

11. Cortes JR, Perez-G M, Rivas MD and Zamorano J: Kaempferol inhibits IL-4-induced STAT6 activation by specifically targeting JAK3. J Immunol 179: 3881-3887, 2007.

12. García-Mediavilla V, Crespo I, Collado PS, Esteller A, Sánchez-Campos S, Tuñón MJ and González-Gallego J: The anti-inflammatory flavones quercetin and kaempferol cause inhibition of inducible nitric oxide synthase, cyclooxygenase-2 and reactive $\mathrm{C}$-protein, and down-regulation of the nuclear factor kappaB pathway in Chang Liver cells. Eur J Pharmacol 557: 221-229, 2007.

13. Arnett FC, Edworthy SM, Bloch DA, et al: The American Rheumatism Association 1987 revised criteria for the classification of rheumatoid arthritis. Arthritis Rheum 31: 315-324, 1988.

14. Lee HY, Jeon HS, Song EK, et al: CD40 ligation of rheumatoid synovial fibroblasts regulates RANKL-mediated osteoclastogenesis: evidence of NF-kappaB-dependent, CD40-mediated bone destruction in rheumatoid arthritis. Arthritis Rheum 54: $1747-1758,2006$
15. Comalada M, Camuesco D, Sierra S, Ballester I, Xaus J, Gálvez J and Zarzuelo A: In vivo quercitrin anti-inflammatory effect involves release of quercetin, which inhibits inflammation through down-regulation of the NF-kappaB pathway. Eur J Immunol 35: 584-592, 2005.

16. Hodgkin PD, Yamashita LC, Coffman RL and Kehry MR: Separation of events mediating B cell proliferation and Ig production by using T cell membranes and lymphokines. J mmunol 145: 2025-2034, 1990.

17. Havsteen BH: The biochemistry and medical significance of the flavonoids. Pharmacol Ther 96: 67-202, 2002.

18. Noh EM, Kim JS, Hur H, et al: Cordycepin inhibits IL-1beta-induced MMP-1 and MMP-3 expression in rheumatoid arthritis synovial fibroblasts. Rheumatology (Oxford) 48: 45-48, 2009.

19. Gates MA, Tworoger SS, Hecht JL, De Vivo I, Rosner B and Hankinson SE: A prospective study of dietary flavonoid intake and incidence of epithelial ovarian cancer. Int J Cancer 121: 2225-2232, 2007

20. Nöthlings U, Murphy SP, Wilkens LR, Henderson BE and Kolonel LN: Flavonols and pancreatic cancer risk: the multiethnic cohort study. Am J Epidemiol 166: 924-931, 2007.

21. Garcia-Closas R, Gonzalez CA, Aqudo A and Riboli E: Intake of specific carotenoids and flavonoids and the risk of gastric cancer in Spain. Cancer Causes Control 10: 71-75, 1999.

22. Komatsu $\mathrm{N}$ and Takayanagi $\mathrm{H}$ : Autoimmune arthritis: the interface between the immune system and joints. Adv Immunol 115: 45-71, 2012.

23. Choy EH and Panayi GS: Cytokine pathways and joint inflammation in rheumatoid arthritis. N Engl J Med 344: 907-916, 2001.

24. Gitter BD, Labus JM, Lees SL and Scheetz ME: Characteristics of human synovial fibroblast activation by IL-1 beta and TNF alpha. Immunology 66: 196-200, 1989.

25. Crofford LJ, Wilder RL, Ristimaki AP, Sano H, Remmers EF, Epps HR and Hla T: Cyclooxygenase- 1 and -2 expression in rheumatoid synovial tissues. Effects of interleukin-1 beta, phorbol ester, and corticosteroids. J Clin Invest 93: 1095-1101, 1994.

26. Tolboom TC, Pieterman E, van der Laan WH, et al: Invasive properties of fibroblast-like synoviocytes: correlation with growth characteristics and expression of MMP-1, MMP-3, and MMP-10. Ann Rheum Dis 61: 975-980, 2002.

27. Martel-Pelletier J, Pelletier JP and Fahmi H: New insights into prostaglandin biology. J Rheumatol 31: 14-16, 2004.

28. Verma IM, Stevenson JK, Schwartz EM, Van Antrerp D and Mitamoto S: Rel/NF-kappa B/I kappa B family: intimate tales of association and dissociation. Genes Dev 9: 2723-2735, 1995.

29. Han Z, Boyle DL, Chang L, et al: c-Jun N-terminal kinase is required for metalloproteinase expression and joint destruction in inflammatory arthritis. J Clin Invest 108: 73-81, 2001

30. McIntyre KW, Shuster DJ, Gillooly KM, et al: A highly selective inhibitor of I kappa B kinase, BMS-345541, blocks both joint inflammation and destruction in collagen-induced arthritis in mice. Arthritis Rheum 48: 2652-2659, 2003.

31. Nishikawa M, Myoui A, Tomita T, Takahi K, Nampei A and Yoshikawa H: Prevention of the onset and progression of collagen-induced arthritis in rats by the potent $\mathrm{p} 38$ mitogen-activated protein kinase inhibitor FR167653. Arthritis Rheum 48: 2670-2681, 2003.

32. Kwon SH, Nam JI, Kim SH, Kim JH, Yoon JH and Kim KS: Kaempferol and quercetin, essential ingredients in Ginkgo biloba extract, inhibit interleukin-1beta-induced MUC5AC gene expression in human airway epithelial cells. Phytother Res 23: 1708-1712, 2009.

33. Kuhns DB, Priel DA and Gallin JI: Induction of human monocyte interleukin (IL)- 8 by fibrinogen through the toll-like receptor pathway. Inflammation 30: 178-188, 2007. 